Conference Article

\title{
The Infulence of Microarc Oxidation Method Modes on the Properties of Coatings
}

\author{
N.Y. Dudareva*, M.M. Abramova and I.V. Alexandrov \\ Ufa State Aviation Technical University, Ufa, Russian Federation, Ufa, 450000, Russia
}

Received 11 September 2014; Accepted 25 September 2014

\begin{abstract}
The experimental studies of the properties of the hardened surface layer, developed by the microarc oxidation method (MAO) on the surface of Al-Si ingots from AK12D alloy have been presented here. The effect of concentration of the electrolyte components on the properties of the MAO coating, such as microhardness, thickness, porosity have been studied. The corresponding regression equations to estimate the influence of the process parameters on the quality of the developed MAO-layer, have been set up.
\end{abstract}

Keywords: microarc oxidation, aluminum AK12D alloy, microstructure analysis, surface

\section{Introduction}

Nowadays aluminum alloys are expanding their application in the advanced machine engineering, engine technology and aircraft industry $[1,2]$. They are used because of their strength, low density and low cost. However the aluminum alloys possess certain disadvantages like low wear, heat and corrosive resistance. There are a few methods of improving wear resistance of parts made with aluminum alloys - for instance, the application of lubricants, inserts protecting the surface, or doping with silicon [3, 4]. However, the most effective methods for solving this problem are the development of coatings and surface modification techniques $[5,6]$.

Microarc oxidation (MAO) is one of these methods, where the modification of the surface of samples made of aluminum, titanium, magnesium and other valve metals tis achieved under the influence of electric charges passing through an electrolyte [7, 8]. The developed MAO-layer consists of the metal oxide substrate and has high microhardness (up to $22 \mathrm{GPa}$ ), wear and heat resistance, high adhesion and corrosive resistance. The thickness of the MAO-layers can reach up to $400 \mu \mathrm{m}$, not affecting significantly the dimensions and required tolerances of the finished parts $[9,10]$.

The in-depth investigations of the structure and properties of the MAO-layer have been carried out by Russian scientists Fedorov V.F., Velikiselskaya N.D., etc. However a large number of works is on MAO-layers on the wrought alloys of the Russian type D16 and V95 [11, 12]. Nowadays it is almost impossible to find any detail information on the properties of the MAO-layer developed on high silicon aluminum alloys and, moreover, about the effect of the MAO-process modes on them. It should be

\footnotetext{
*E-mail address: natalia_id@mail.ru

ISSN: 1791-2377 @ 2014 Kavala Institute of Technology. All rights reserved.
}

stated that is difficult to coat them with the MAO method: Forming a hardened layer is possible only under specific modes within very tight tolerances. Besides this difficulty, the quality of the layer is not always satisfactory. In connection with this, the aim of this work is to investigate the effect of the MAO process modes on properties and structure of MAO-layers, developed on the surface of samples from high-silicon aluminum alloy AK12D, a widely used engineering structural material.

\section{The Methodology of the Investigation}

The high silicon aluminum alloy AK12D OST 192014-90 has been selected as the material for the samples. The samples have been cut out of a round rod producing a disk specimen with a diameter of $64 \mathrm{~mm}$ and thickness of $5 \mathrm{~mm}$. The surface area subjected to processing was $7405 \mathrm{~mm}^{2}$. The surface had not been washed up or degreased.

The investigation of the samples has been carried out according to the plan, which is a half-replicate of the complete factorial experiment $2^{3-1}$ [13]. The following factors have been chosen for the experiment: the alkali concentration in the electrolyte $-C_{K O H}, \mathrm{~g} / \mathrm{l}$; the concentration of the liquid glass $\left(\mathrm{Na}_{2} \mathrm{SiO}_{3}\right)$ in the electrolyte $-C_{L G}, \mathrm{~g} / \mathrm{l}$; condenser capacity of the setting $C, \mu \Phi$. During processing the ratio of cathode to anode current has been kept constant $I_{a} / I_{c}=1$, while the concentration of potassium hydroxide has been changed from 1.5 to $3.5 \mathrm{~g} / 1$, the concentration of $\mathrm{Na}_{2} \mathrm{SiO}_{3}$ - from 1.5 to $3.5 \mathrm{~g} / \mathrm{l}$, the capacitance - from 200 to $400 \mu \mathrm{F}$. In the experiment the output parameters were: $y_{1}$ - the thickness of the MAO-layer, $h, \mu \mathrm{F} ; y_{2}-$ the microhardness of the layer, $H_{\mu}, \mathrm{GPa} ; y_{3}-$ the porosity of the layer, $p, \%$. The thickness is the characteristic of the MAO-layer, which allows 
estimating the part life working in friction, the microhardness affects the wear resistance of the surface, while the porosity is indicative of the resistance to corrosion. There were five samples. The MAO process was kepu up until the complete sparking termination on the processed surface.

After developing the MAO-layer the samples were sectioned and their thickness, microhardeness and porosity of the MAO-layer were measured. The measurement of the thickness of the coatings and porosity was carried out with a scanning electron microscope (SEM) "JEOL JSM 6390" at $\times 500$ and $\times 1000$ magnifications, porosity was measured in the mode of the back-scattered electrons. Hardness measurement of the MAO-layer in Vickers was carried out with a Struers Durami, instrument for a load of $100 \mathrm{~g}$ applied for $10 \mathrm{sec}$. There were at least 5 measurements taken for hardnes and 4 to 6 for the thickness of the coating.

\section{Results and Discussion}

Five samples were coated with MAO method in various modes (Fig. 1). Analyzing their appearance, it is possible to claim that the conditions of developing the hardened surface layer influence significantly the color and appearance of the MAO-layer.

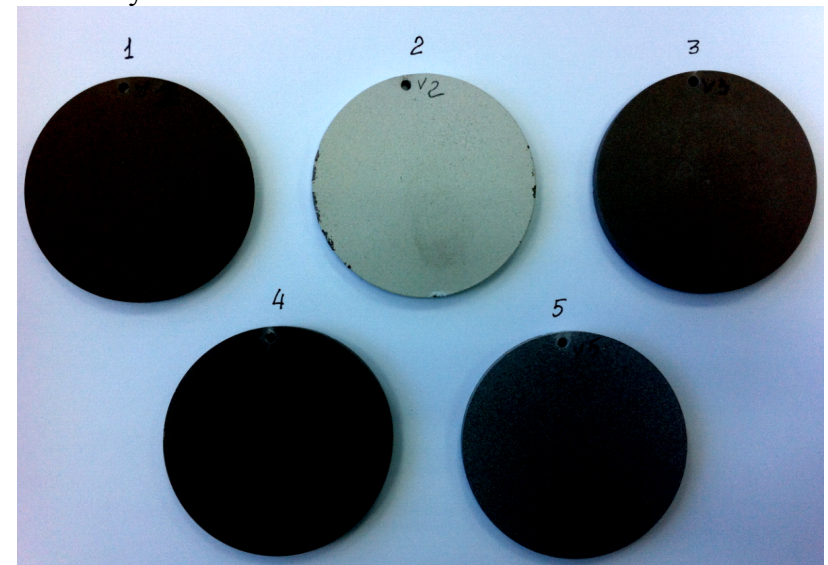

Fig. 1. Samples after MAO

In Fig. 2 there is the image of the microstructure of the MAO-layer in the cross section for the samples with the minimum and maximum thickness. Depending on the process mode the average value of the MAO-layer thickness changes from $23 \mu \mathrm{m}$ for sample № 3 to $114 \mu \mathrm{m}$ for sample № 2 (Table 1).

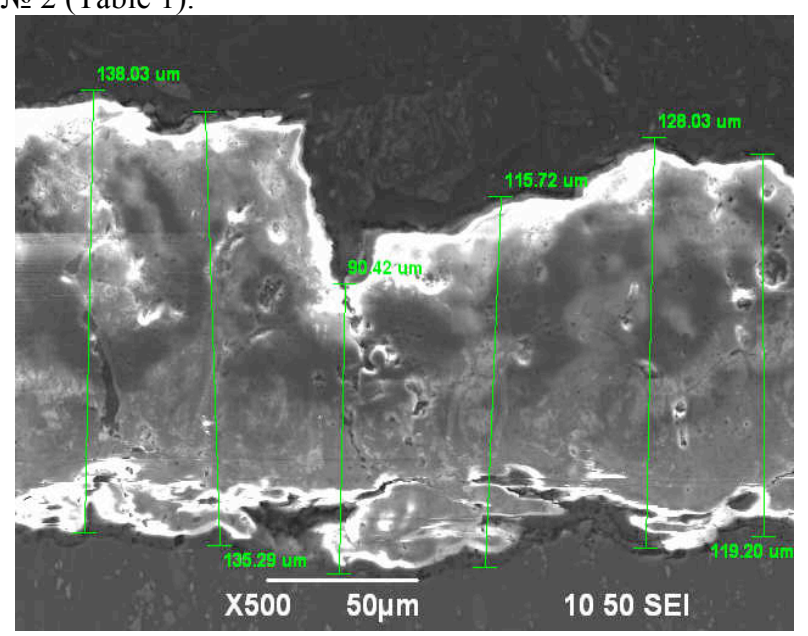

a

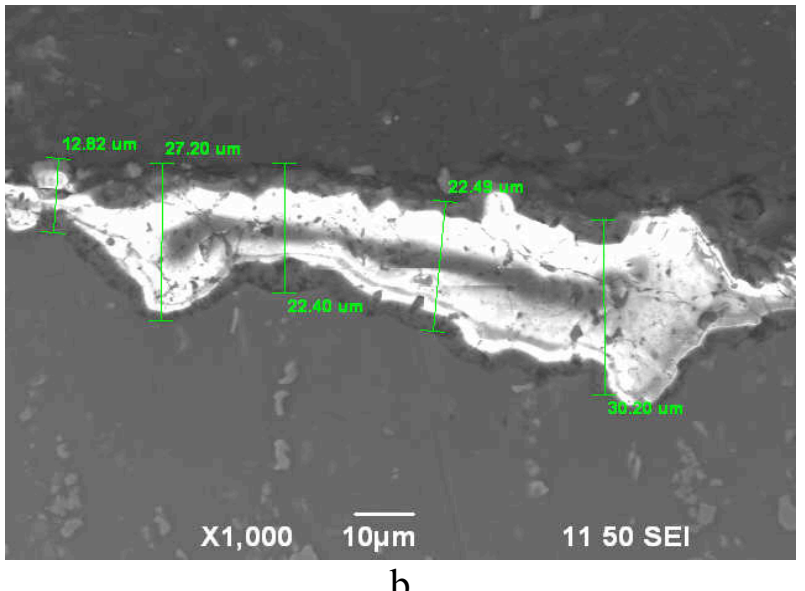

$\mathrm{b}$

Fig. 2. The thickness of the MAO-layer: a) sample № 2 with maximum thickness; b) sample № 3 with minimum thickness

Table 1. Thickness, microhardness and porosity of the MAO-layer

\begin{tabular}{|c|c|c|c|c|c|c|}
\hline \multirow{2}{*}{$\begin{array}{c}\text { № } \\
\text { mode } \\
\text { (sam } \\
\text { ple) }\end{array}$} & \multirow{2}{*}{$\begin{array}{c}\text { Average } \\
\text { thichness } \\
\text { of the } \\
\text { MAO- } \\
\text { layer, } \\
h_{\text {aver, }}, \mu \mathrm{m}\end{array}$} & \multicolumn{2}{|c|}{$\begin{array}{l}\text { Microhardne } \\
\text { ss, } H \mu, \text { GPa }\end{array}$} & \multicolumn{2}{|c|}{$\begin{array}{c}\text { Porosity, } p, \\
\%\end{array}$} & \multirow{2}{*}{$\begin{array}{c}\text { Characte } \\
\text { ristics of } \\
\text { the } \\
\text { MAO- } \\
\text { layer } \\
\text { thickness }\end{array}$} \\
\hline & & $\begin{array}{c}\text { Max } \\
\text { imu } \\
\text { m }\end{array}$ & $\begin{array}{c}\text { Aver } \\
\text { age } \\
\text { valu } \\
\text { e }\end{array}$ & $\begin{array}{c}\text { Max } \\
\text { imu } \\
\text { m }\end{array}$ & $\begin{array}{c}\text { Aver } \\
\text { age } \\
\text { valu } \\
\text { e }\end{array}$ & \\
\hline 1 & 50 & 9.0 & 6.5 & 14.9 & 6.3 & $\begin{array}{c}\text { Not } \\
\text { homogen } \\
\text { eous }\end{array}$ \\
\hline 2 & 114 & 12.0 & 7.3 & 16.6 & 4.5 & $\begin{array}{c}\text { homogen } \\
\text { eous }\end{array}$ \\
\hline 3 & 23 & 8.8 & 6.2 & 21.3 & 12.9 & $\begin{array}{c}\text { not } \\
\text { homogen } \\
\text { eous }\end{array}$ \\
\hline 4 & 43 & 7.0 & 5.8 & 15.4 & 6.3 & $\begin{array}{c}\text { Not } \\
\text { homogen } \\
\text { eous }\end{array}$ \\
\hline 5 & 73 & 12.0 & 7.4 & 16.9 & 5.2 & $\begin{array}{c}\text { homogen } \\
\text { eous }\end{array}$ \\
\hline
\end{tabular}

In Fig. 3 the distribution of porosity and microhardness of the MAO-layer for samples № 2 and № 3 is shown. The summary of the effects of these factors for all 5 samples are shown in Table 1.

Based on the experimental data, three equations of regression [13] have been set up. They show the effect of the modes of the MAO-process on the properties of MAOlayers:

$$
\begin{aligned}
& h_{\text {aver }}=-995+176 \cdot C_{K O H}+166 \cdot C_{L G}+1.679 \cdot C- \\
& -0.155 \cdot C_{\mathrm{KOH}} \cdot C_{L G} \cdot C \text {; } \\
& H_{\mu a v e r}=-51+9.6 \cdot C_{K O H}+9.8 \cdot C_{L G}+0.0924 \cdot C- \\
& -0.0095 \cdot C_{\mathrm{KOH}} \cdot C_{L G} \cdot C \text {; } \\
& p_{\max }=27.525-2.55 \cdot C_{K O H}+0.4 \cdot C_{L G}-0.02687 \cdot C+ \\
& +0.0015 \cdot C_{\mathrm{KOH}} \cdot C_{L G} \cdot C \text {; } \\
& p_{\text {aver }}=149.45-25.1 \cdot C_{\mathrm{KOH}}-21.8 \cdot C_{L G}-0.2337 \cdot C+ \\
& +0.023 \cdot C_{K O H} \cdot C_{L G} \cdot C
\end{aligned}
$$


where $h_{\text {aver }}$ - the average thickness of the MAO layer, $\mu \mathrm{m}$; $H_{\mu a v e r}$ - the average value of microhardness, GPa; $p_{\max }-$ the maximum value of the porosity, $\% ; p_{\text {aver }}-$ the average value of the porosity, $\% ; C_{K O H}-$ the concentration of potassium hydroxide $(\mathrm{KOH})$ in the electrolyte, $\mathrm{g} / \mathrm{l} ; C_{L G}-$ concentration of the liquid glass $\mathrm{Na}_{2} \mathrm{SiO}_{3}$ in the electrolyte, $\mathrm{g} / \mathrm{l} ; C$ - the capacity of the condensers of the MAO setting, $\mu \mathrm{F}$.
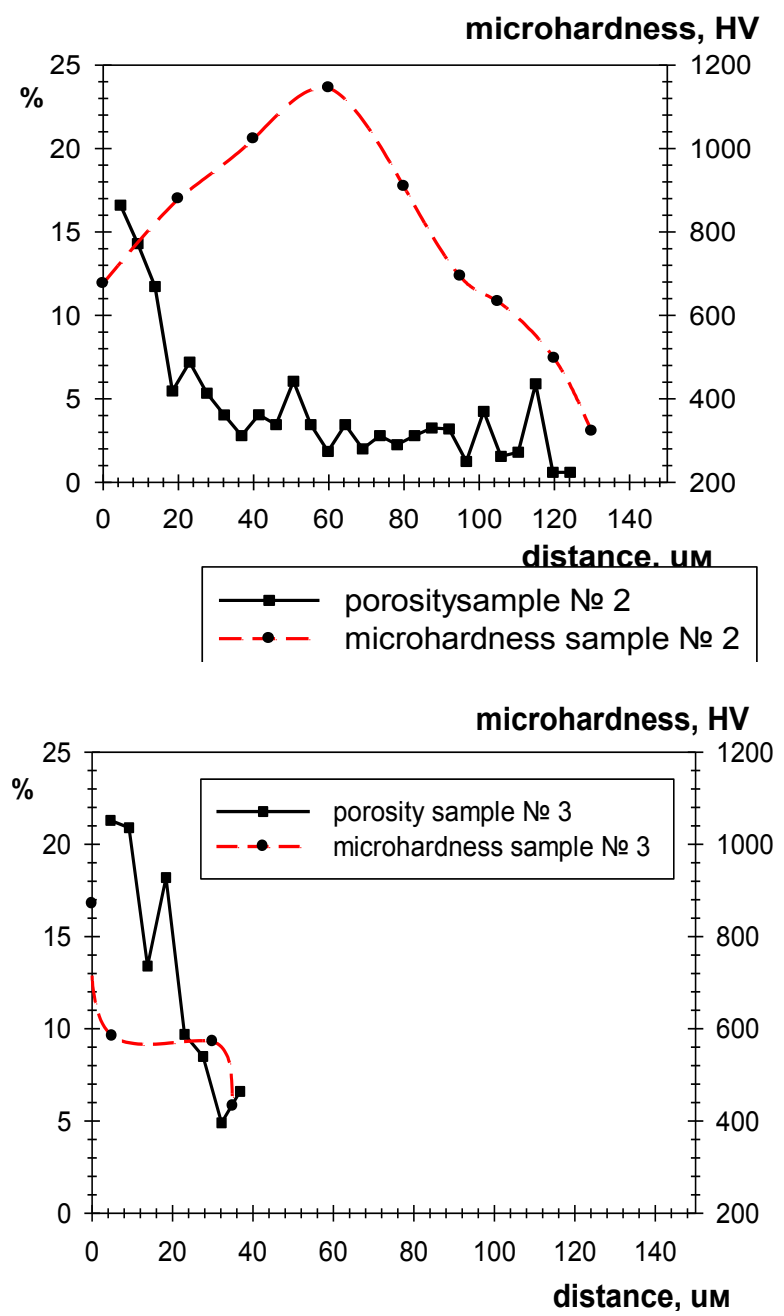

Fig. 3. Porosity and microhardness of the MAO-layer away from the parent material a) the sample № 2; b) the sample № 3

From these data two processing modes stand out, № 2 and 5, for the quality of the coating produced for its homogeneity, maximum thickness and microhardness. The homogeneous surface layers have maximum thickness and microhardness for these modes. Both of these modes are characterized by high concentrations $\mathrm{KOH}$ and $\mathrm{Na}_{2} \mathrm{SiO}_{3}$ in the electrolyte and greater values of current densities: mode № $2-\mathrm{KOH}-3.5 \mathrm{~g} / 1, \mathrm{Na}_{2} \mathrm{SiO}_{3}-3.5 \mathrm{~g} / 1$, current density $j-$ $12.4 \mathrm{~A} / \mathrm{dm}^{2}$; mode № 5 - $\mathrm{KOH}-2.5 \mathrm{~g} / 1, \mathrm{Na}_{2} \mathrm{SiO}_{3}-2.5 \mathrm{~g} / 1$, current density $j-9,2 \mathrm{~A} / \mathrm{dm}^{2}$;

Analyzing the equation of linear regression and the experiments it can be shown that the mode of the process greatly affects the properties of the developed layers. In such an analysis it is important to pay attention to the value of regression coefficients, which estimate the contribution of each factor (the parameters of the mode of MAO-process) into the response function (the properties of the MAOlayer). The increase of $\mathrm{KOH}$ concentration in the electrolyte influences the increase of the thickness of the MAO-layer. This can be explained by the fact that only potassium hydroxide is responsible for the intensity of MAOprocessing and influences directly the density of anode current, increasing the thickness and microhardness. The increase of $\mathrm{Na}_{2} \mathrm{SiO}_{3}$ concentration also increases microhardness, thickness and maximum porosity of the MAO-layer. Analyzing the regression equations one can point out that $\mathrm{Na}_{2} \mathrm{SiO}_{3}$ influences the properties of the MAOlayer in a similar way as $\mathrm{KOH}$. This is probably related to $\mathrm{Na}_{2} \mathrm{SiO}_{3}$ increasing the process intensity for the high silicon aluminum alloys due to the affinity of the silicon compounds to the metal of the sample. The capacitance influences the thickness of the MAO-layers, as it increases the intensity of the processing. The increase of the electrolyte components almost equally affects the average value of the porosity of the MAO-layer and leads to its decrease. Herein, the value of the maximum porosity depends only on the quantity of $\mathrm{KOH}$ in the electrolyte and decreases, when its concentration rises. It's possible to suggest that the increase of the concentration of electrolyte components and setting capacity causes the increase of the MAO processing intensity, which in its turn decreases pore concentration.

\section{Conclusions}

As a result of this investigation it has been found out that the modes of the MAO process influence greatly the properties of the developed surface layers (thickness, microhardness and porosity). The equations of regression based on the results of the fractional factorial experiment, show that $\mathrm{KOH}$ has the most influence on the properties of the MAO layers, the least one is $\mathrm{Na}_{2} \mathrm{SiO}_{3}$. But both of them favour the increase of the MAO-layer in casted high silicon alloys. The least effect on the properties of MAO-layer is from the capacitance of the setting capacitors.

\section{Acknowledgment}

This work was produced during the joint project between USATU (Ufa State Aviation Technical University) and UMPO (Ufa Engine Industrial Association) with title "Elaboration and industrial development of high-precision shaping coordinated technologies and superficial hardening of responsible details from Al-alloys with heightened constructional energy efficiency", implemented under the contract №40/10-30976 sponsored by the Ministry of Education and Science of the Russian Federation (contract №02.G25.31.0010 between UMPO and the Ministry of Education and Science of the Russian Federation) through the Resolution of the Russian Federation Government № 218 from April 9, 2010. 


\section{References}

[1] S. Beer, Kolbenschmidt Aluminium-Technologie AG. Anlaufmanagement in der Automobilindustrie erfolgreich umsetzen. Springer, p. 43-52 (2008).

[2] E.K. Solovih. Tribology problems. 2, c. 47-57 (2009).

[3] S.V. Gnedenkov, O.A. Khrisanfova, A.G. Zavidnaya, S.L. Sinebruyhov, A.N. Kovryanov, T.M. Skorobogatova, P.S. Gordienko. Metals protection. 35 (5), C. 527 - 530 (1999).

[4] Cylinder Components: Properties, Applications, Materials. Mahle $\mathrm{GmbH}$, Stuttgart (2010).

[5] G.W. Malaczynskietal. Journal of materials engineering and performance. 6 (2), p.223-239 (1997)

[6] A.P. Efremov. News of Higher Educational Institutions. Physics. 35 (5), C. 32-43 (1989).

[7] I.V.Suminov. Microarc oxidation theory, technology and equipment Ecomet, Moscow (2005).

[8] V.I. Chernenko, LA Snezhko, II Papanova. Preparation of anodic coatings spark electrolysis. Chemistry, Leningrad (1991).

[9] G.A. Markov, V.I. Belevantsev, O.P. Terleeva, E.K. Shulepko, V.I. Kirillov. Friction and wear. 9 (2), pp. 286 - 290 (1988).

[10] A.I. Gorchakov, Y. Shcherbakov, N.M. Borodin. Metal Technology. 1, pp. 39-41 (2006).

[11] V.P. Alekhine, V.A. Fedorov, S.I. Boulichev, O.A. Turpenko. Physics and chemistry of materials processing. 5, P.121-123 (1991).

[12] P.I. Butyagin, E.V. Khokhryakov, A.I. Mamaev. Metal Technology. 1, pp. 36-39 (2005).

[13] Y.P. Adler, E. Markov, Y. Granovsky. Planning an experiment in finding optimal conditions. Publishing House "Nauka", Moscow (1976). 